\title{
ESTUDO, AO MICROSCÓPIO ÓPTICO E ELETRÔNICO, DO RIM DE CÃES NATURAL E EXPERIMENTALMENTE INFECTADOS COM Leishmania (Leishmania) chagasi
}

\author{
Washington Luiz TAFURI (1), Marilena Suzan Marques MICHALICK (2), Magno DIAS (1), Odair GENARO (3), \\ Virginia Hora Rios LEITE (4), Alfredo José A fonso B ARBOSA (4), Eduardo Alves BAMBIRRA (4), \\ Carlos Alberto da COSTA (5), Maria Norma MFILO (2) \& Wilson MAYRINK (2)
}

\begin{abstract}
RESUMO
Os autores estudam os rins de 4 cāes infectados com Leishmania (Leishmania) chagasi. Dois animais (um macho e uma fèmea) naturalmente infectados foram sacrificados 18 meses após sua permanência no laboratório. Dois machos foram inoculados por via endovenosa, com $1 \times 10^{6}$ promastigotas da cepa $\mathrm{MHO} / \mathrm{BR} / 70 / \mathrm{BH} 46$ e sacrificados após 18 meses e 2 anos, respectivamente. Em todos os animais os rins estavam lesados. As alteraçoes encontradas foram: (1) glomerulonefrite mesangioproliferativa focal ou difusa, com pronunciada hipertrofia e hiperplasia das células mesangiais e com alargamento da matriz; (2) espessamento da membrana basal com depósitos eletrondensos: (3) nefrite intersticial intertubular crónica com exsuda çāo plasmocitária intensa. (4) degeneraçāo albuminosa dos túbulos renais. Baseados nos achados os autores discutem os prováveis mecanismos patogenéticos.
\end{abstract}

UNITERMOS: Nefropatia parasitária: Leishmania (L.) chagasi: Calazar canino.

\section{INTRODUÇÃO}

A leishmaniose visceral ( $L$ V) causada, no Brasil, pela Leishmania (Leishmania) chagasi, é uma doença de evoluçāo crônica capaz de de terminar a morte do hospedeiro, quando não tra tada. Como o parasito é intracelular do Sistema Mononuclear Fagocitário. a majoria das altera çōes histopatológicas ocorrem ao acaso. mas predominantemente nos órgãos do sistema imu nitário e do fígado. No entanto, alteraçoes renais tèm sido relatadas em casos humanos (UEBEL, 1951: BOGLIOLO, 1956; DE PAOLA \& SILVA. 1966; ANDRADE \& YABUKI, 1972; DUARTE et al., 1983: DE BRITO et al., 1975) e em hamster (HINGHAIS et al, 1964; DUARTE et al,, 1978; DUARTE, 1975; AGU et al., 1981; OLIVEIRA et âl, 1985). No cão, reservatório doméstico da

(1) Departamento de Ciências Biológicas - Universidade Federal de Ouro Preto, Ouro Preto, MG, Brasil.

(2) Departamento de Parasitologia -... Instituto de Ciencia: Biologicas -. Universidade Federal de Minas Gerais, Belo Horizonte. MG. Brasil.

(3) Instituto Nacional de Pesquisas da Amazonia - Manaus, AM, Brasil

(4) Departamento de Anatomia Patológica - Faculdade de Medicina - Universidade Federal de Minas Gerais, Belo Horizonte. MG, Brasil.

(5) Departamento de Análises Clínicas e Toxicologicas - Faculdade de Farmácia - Universidade Federal de Minas Gerais Belo Horizonte. MG. Brasil

Endereço para correspondência: Dr. Washington Luiz Tafuri. Departamento de Parasitologia do ICB UFMG. Caixa Postal 2486. CEP 31270 Belo Horizonte, Minas Gerais, Brasil. 
TAFURI, W. L.; MICHALICK, M. S. M.: DIAS, M.; GENARO, O.; LEITE, V. H. R.; BARBOSA, A. J. A.; BAMBIRRA, E. A.: COSTA, C. A. da; MELO, M. N. \& MAYRINK. W. - Estudo, ao microscópio óptico e eletrónico, do rim de cảes natural e experimentalmente infectados com Leishmania (Leishmania) chagasi. Rev. Inst. Med. trop. S. Paulo, $31(3)$ : 139-145, 1989.

LV, as investigaçōes clássicas de DEANE, 1956 e ALENCAR, 1959, cobriram basicamente todos aspectos epidemiológicos da doença. No entanto, sāo escassos os estudos histopatológicos em cāes, especialmente os relativos às alteraçōes re nais (CHUNG et al., 1940; BRENER, 1957; Mc CONNEL et al., 1970; AYALA, 1973; GEORGE, 1976; CORBEIL et al., 1976).

O propósito do presente trabalho é portanto, o de estudar sistematicamente os rins de càes infectados natural e experimentalmente com $\mathbf{L}$. (L.) chagasi, no pressuposto de se conhecer me lhor a patogenia da glomerulopatia.

\section{MATERIAL E MÉTODOS}

Foram utilizados dois cães adultos (macho e fêmea), de idade ignorada, com calazar natural e provenientes de Teófilo Otoni, MG, mantidos no canil do Instituto de Ciências Biológicas da UFMG durante 18 meses e dois cães machos, de raça náo definida, que aos dois meses de idade receberam $1 \times 10^{6}$ promastigotas da cepa $\mathrm{MHO}$ $\mathrm{BR} / 70 / \mathrm{BH} 46$ por via endovenosa e mantidos em canil por dois anos. Os animais foram sacrifi cados por choque elétrico. As autópsias foram completas, coletando-se fragmentos de todos os órgãos. O material foi fixado em formol salina a $10 \%$, tamponado, pH 7.2 e fragmentos da corti cal e medular do rim foram fixados também em aldeido glutárico a $2 \%$ em tampão fosfato, $\mathrm{pH}$ 7.2 .

Para os estudos à microscopia óptica, os fragmentos dos rins foram incluídos em parafina, cortados na espessura de 2.5 micrómetros e cora dos pela hematoxilina eosina, tricrômico de Gomori, PAS, prata metenamina e vermelho Congo (pesquisa de amiloide). Foram realizados tam bém em alguns cortes, a reação PAP (peroxi dase) usando-se anti-soro anti-Leishmania (BARBOSA et al., 1986).

Para o estudo à microscopia eletrônica os fragmentos fixados em aldeido glutárico $2 \%$ foram tratados com tetróxido de ósmio $1,0 \%$, desi dratados, incluidos em EPON, cortados em ul tramicrótomo Reichert, corados pelo Reynolds e examinados no ME EM 9-S2, Zeiss.

\section{RESULTADOS}

Os resultados laboratoriais e os dados de necrópsia dos animais natural e experimentalmente infectados sāo apresentados no Quadro 1.

\section{Análise dos rins}

Todos os 4 animais apresentavam os rins com degeneração albuminosa (pálidos, úmidos e brilhantes) e as lesões renais eram evidentes ora mais, ora menos intensas nos vários cortes examinados. Como os achados foram bastante uniformes, será feita aqui uma análise em conjunto dos rins dos animais infectados natural e experimentalmente.

\section{Microscopia óptica}

Tanto no rim direito quanto no esquerdo as lesōes encontradas podem ser assim discriminadas:

Os glomérulos, em sua maioria, mostravam nitida proliferaçāo mesangial focal ou difusa, com intenso espessamento da matriz. Espessamentos irregulares da membrana basal; luz capi lar pérvia (alguns granulócitos neutrófilos e célu las mononucleadas livres ou aderentes ao endotélio) ou nāo (ocluída devido a compressão extrínseca). Vez por outra, observou-se aderéncia entre o folheto parietal e o visceral da cápsula de Bowmann. Muitos glomérulos apresentavamse fibrosados e hialinizados. Foi freqüente o achado de infiltrado intertubular na medular e cortical, de células plasmáticas, às vezes intenso, com conseqüente degeneraçäo albuminosa dos túbulos, com ou sem cilindros hialinos na luz. Em todos os rins foi negativa a pesquisa amiloide e de parasitos. Em alguns cortes foi positiva a reação do $P A P$ no citoplasma de células mononucleadas, possivelmente macrófagos (Fig. 1A e B).

\section{Microscopia eletrônica}

Os achados mais marcantes e constantes foram:

1. Uma pronunciada proliferação das células mesangiais (Fig. 2) com intenso alargamento 
TAFURI, W. L.: MICHALICK, M. S. M.; DIAS, M.; GENARO, O; LEITE, V. H. R.; BARBOSA, A. J. A.: BAMBIRRA, E. A. COSTA. C. A. da: MELO, M. N. \& MAYRINK, W. - Estudo, ao microscopio óptico e eletronico, do rim de caes natural e experimentalmente infectados com Leishmania (Leishmania) chagasi. Rev. Inst. Med. trop. S. Paulo, $31(3): 139145,1989$.

QUADRO 1

Aspectos gerais observados em 4 cāes infectados experimental ou naturalmente com Leishmania (L.) chagasi

\begin{tabular}{|c|c|c|c|c|}
\hline \multirow[t]{2}{*}{$\begin{array}{l}\text { Aspectos gerais } \\
\text { Observados }\end{array}$} & \multicolumn{2}{|c|}{$\begin{array}{c}\text { Animais naturalmente } \\
\text { infectados }\end{array}$} & \multicolumn{2}{|c|}{$\begin{array}{c}\text { Animais experimentalmente } \\
\text { infectados }\end{array}$} \\
\hline & Cão 1 & Cão 2 & Cão 1 & Cảo 2 \\
\hline Reação de Fixação do complemento & $1: 160$ & $1: 160$ & $1: 360$ & $1: 160$ \\
\hline Lesōes verrucosas & Numerosas & Numerosas & $(-)$ & $(-)$ \\
\hline Alopécia & $1+1$ & $1+1$ & $(+)$ & $1+1$ \\
\hline Hepatoesplenomegalia & $1+1$ & $(+)$ & $(+)$ & $1+1$ \\
\hline Congestão de baço e fígado & $1+1$ & $(+)$ & $(+1)$ & $(+1)$ \\
\hline Hipertrofia dos linfonodos abdominais & $1+1$ & $(+)$ & $(+)$ & $(+)$ \\
\hline $\begin{array}{l}\text { Parasito presente no baço, fígado, medula } \\
\text { ossea e linfonodo }\end{array}$ & $1+1$ & $(+)$ & $(+)$ & $(+)$ \\
\hline Outros dados & $1-1$ & $\begin{array}{c}\text { Congestāo } \\
\text { e edema } \\
\text { dos mesos }\end{array}$ & $\begin{array}{c}\text { Criptorquidia } \\
\text { esquerda }\end{array}$ & $(-)$ \\
\hline
\end{tabular}

( + presente $\quad(-)$ ausência do dado

da matriz. Nesta, era freqüente a deposiçāo de material eletrondenso de forma e volume variá vel, de permeio com estruturas filamentosas orientadas em vários sentidos, semelhantes ou não as do colágeno (Fig. 3). A matriz, por vezes, se insinuava entre lâminas basais, como se esti vesse dissecando-as;

2. Espessamento irregular da membrana basal (MB), com variaçōes entre 100 e $200 \mathrm{~nm}$. Sua eletrondensidade era uniforme, não se identificando as lâminas raras interna e externa. $\mathrm{Na}$ espessura $\mathrm{MB}$, foi frequentissimo o encontro de depósitos eletrondensos, por vezes muito volu mosos, porosos, finamente granulosos ou entāo compactos muito homogêneos. Nestas áreas a MB era ainda mais espessa (Figs. 4A e 4B). Depó sitos sub-endoteliais também foram vistos se bem que em menor número:

3. Os podócitos, por vezes, mostravam-se degenerados, vacuolizados e com fusāo dos prolongamentos terciários, junto da MB (Fig. 5):
4. Deformidade da luz capilar devido a compressão extrinseca, chegando mesmo a sua total oclusāo. Naqueles pervios, podia-se ver, com certa freqüência, granulócitos neutrófilos junto ao endotélio, emitindo pseudópodos. Foi freqüente a tumefaçảo e vacuolização endoteliais (Figs. 5 e 6):

5. Muitos glomérulos estavam totalmente fibrosados;

6. Entre os túbulos contorcidos proximais, distais e coletores, com denegeraçāo albuminosa, foi frequente o encontro de intenso infiltrado plasmocitário (Fig. 7).

\section{DISCUSSÃO}

De um modo geral, as lesôes renais, por nós observadas, tanto no animal natural quanto no experimentalmente infectado foram semelhan tes quando comparadas com aquelas vistas no 
TAFURI. W. L.: MICHALICK, M. S. M.: DIAS, M: GENARO. O.: LEITE. V. H. R : BARBOSA. A. J. A.: BAMBIRRA. E. A. COSTA. C. A da: MFLO. M. N. \& MAYRINK. W. - Estudo, ao microscopio optico e eletronieo, do rim de caes natural e experimentalmente infectados com Leishmania (Leishmanial chagasi. Rev. Inst. Med. trop. S. Paulo, 31(3): 139 145, 1989
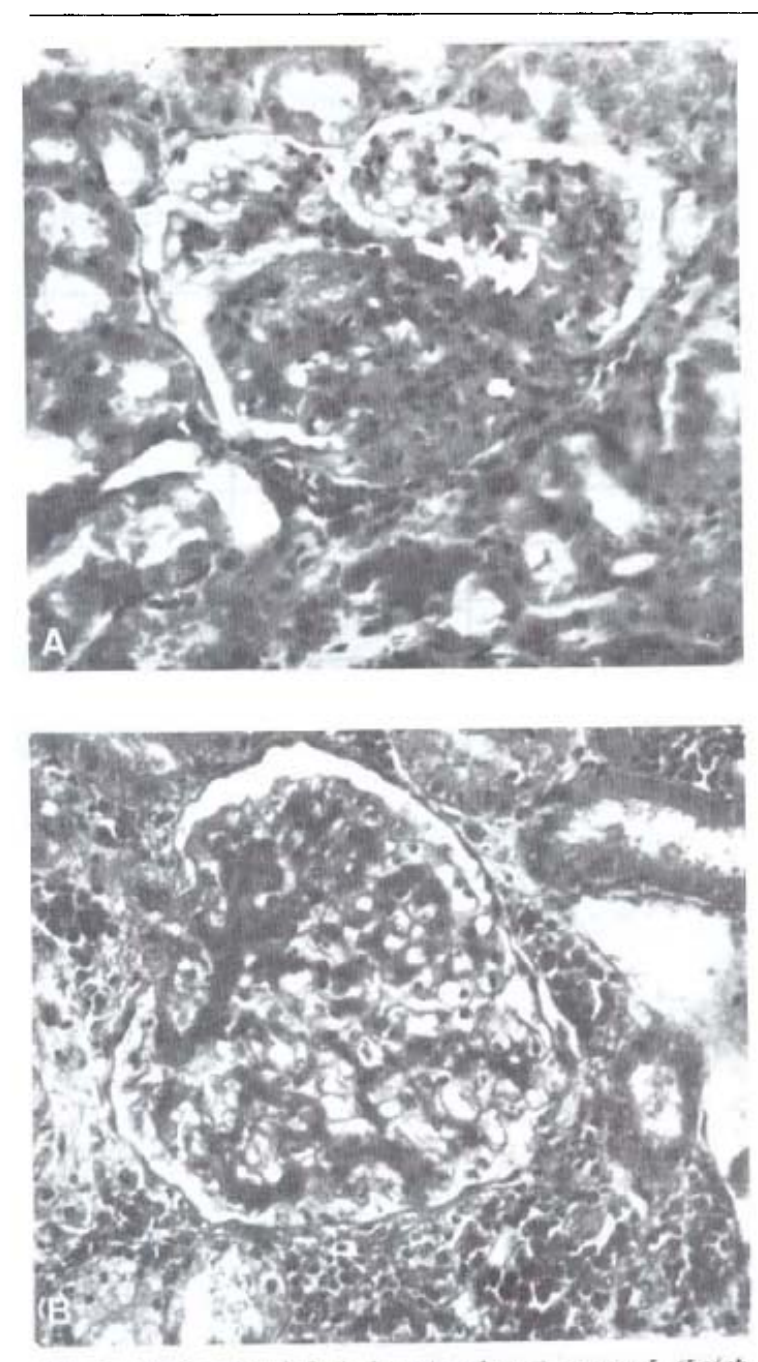

Fig. 1-A. B - Câo infectado naturalmente com a L. Reishmania) chagasi com idade nâo definida. Cortical do rim direito, cortes semi-finos. Azul de tolaidina.

A Gomerulo apresentando nitida lesâ focal iespessamento do mesangio: fibrose e oclusì da luz das alças glomeru lares: aderência parcial do folheto visceral ao parietal da capsula de Bowmann

B. Glomérulo aumentado de volume com espessamento di. fuso do mesangio. Alças capilares. em sua maioria pervias. Infiltrado de células mononucleadas entre os tubu los renais.

homem (BOGLIOLO, 1956) e no hamster (HIN GHAIs et al.. 1964: DUARTE, 1975; OLIVEIRA et al., 1985). A nefrite intersticial por nos obser. vada parece similar às descritas no cāo por CHUNG et al. 1940; TOMÉ, 1956 e BRENER. 1957. Apenas nảo se confirmou como no homem

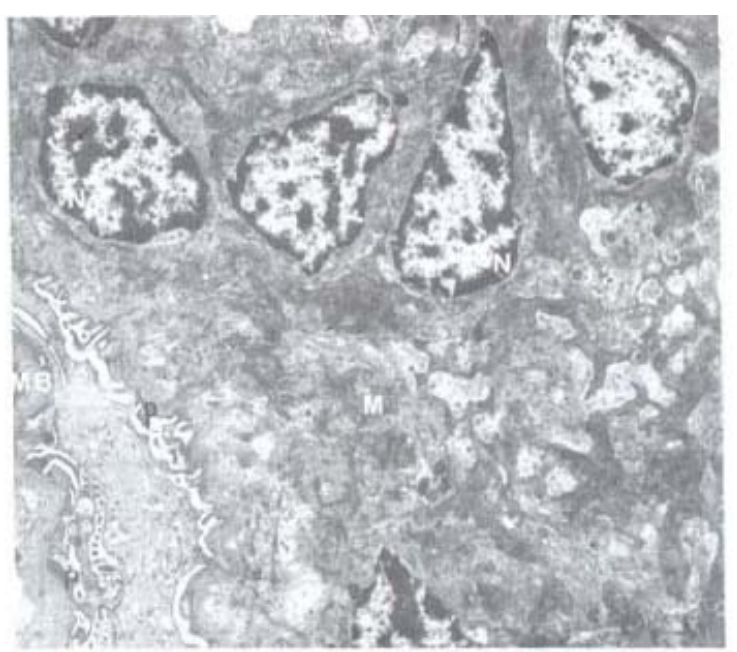

Fig. 2 - Cao infectado experimentalmente com a L. (Leish. mantal chazasi e sacrificado 2 anos apos a infeçăo. Cortical de rim direito. Hiperplasta das celulas mesangiais com intensc alargamento da matriz devido a material amorfo e filamentoso de eletrondensidade variàvel. Núcleo das células mesangiais (N): matriz iM): podócito (P); Membrana basal do glomerulo (MB) $\times 7880$

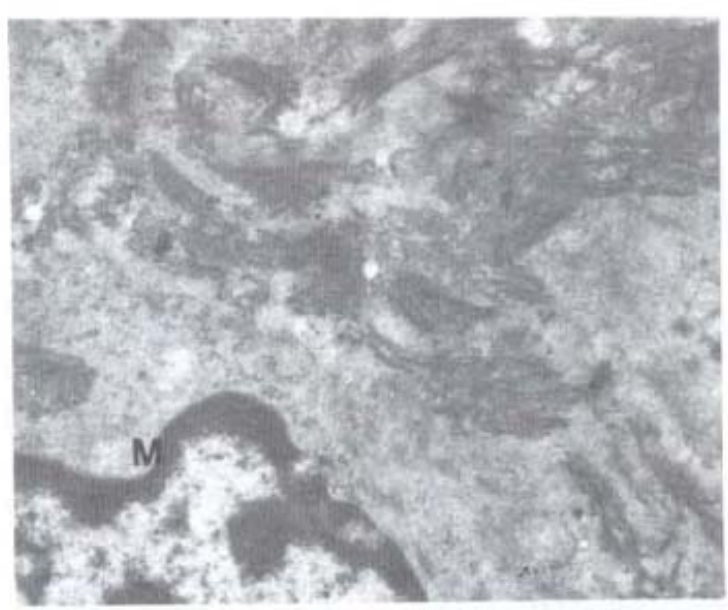

Fig 3 - Câo infectado naturalmente com a $L$. (Lejshmania) chazasj com idade nas definida, Rim direito. Parte de um klomerulo pareialmente fibrosado. Matriz mesangial com estruturas filamentosas orientadas em varios sentidos semelhan tes a colágeno. Núcleo da célula mesangial (M), x 20140.

e no hamster. a presença de amiloide na matriz mesangial. No entanto CHUNG et al., 1940 observou uma fraca reaçāo amiloide em glomerulos de um cảo entre doze estudados e acometidos 
TAFURI. W. L.: MICHALICK. M S. M. DIAS, M. GENARO. O.; LEITE, V. H. R ; BARBOSA. A. J. A.; BAMBIRRA E. A. costa, C. A da: MELO, M. N. \& MAYRINK, W. - Estudo, ao microscópio óptico e eletronico, do rim de caes riatural e experimentalmente infectados com Leishmania (Leishmania) chagasi. Rev. Inst. Med. trop. S. Paulo, 31 (3) 139145,1989
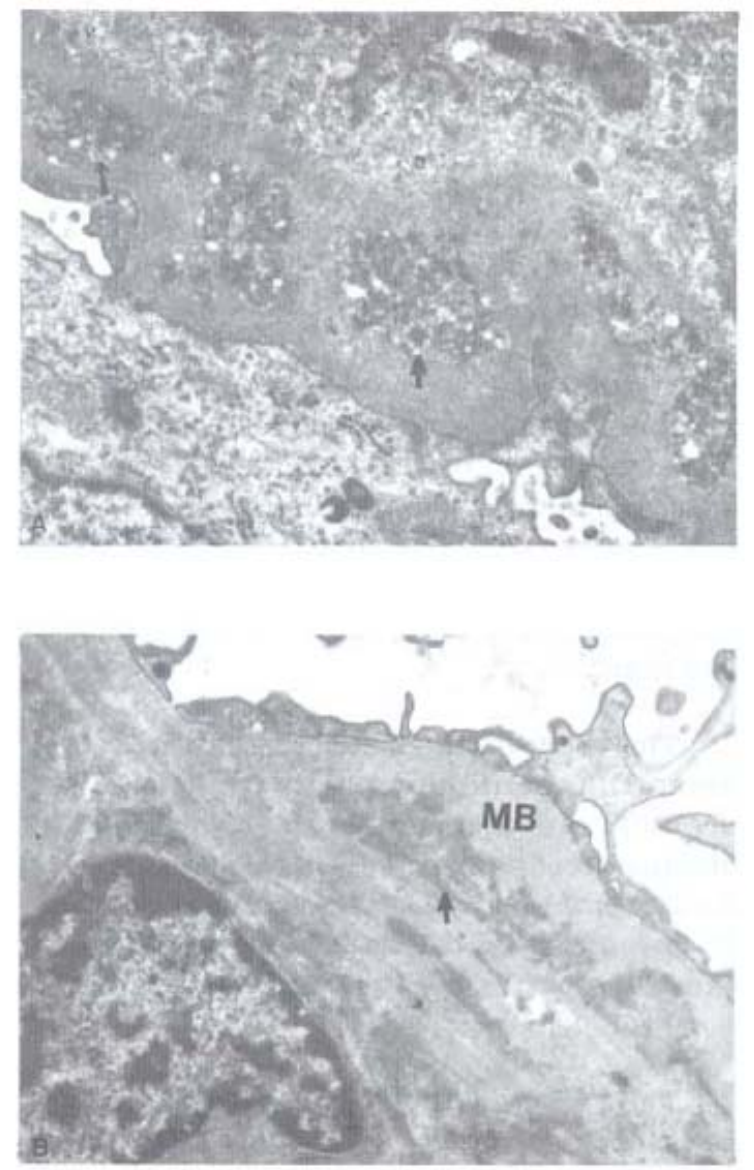

Fig. 4 - A e B - Calo infectado natural (A) e experimental. mente (B) com a L. (Leishmania) chagasi, Rim direito, Parte de um glomerulo mostrando intenso espessamento da MB, com vários depositos eletrondensos granulosos ou homogèneos ise tasi na sua espessura. $\times 20480$.

peia LV. Chamou-nos atenção o intenso exsu dato de células plasmáticas no interstício inter tubular e a presença de alguns macrófagos com PAP positivo, indicando provavelmente a pre sença de exoantigenos. O PAP foi também positivo nas lesōes verrucosas da pele. É possivel. portanto, que no rim estes antígenos (Ag) possam interagir com anticorpos (Ac) especificos formando aí complexos $\mathrm{AgAc}$ responsáveis pelas respostas celulares mesangioproliferativas. Aliás, DE BRITO et al., 1975: WEINSINGER et al., 1978, DUARTE, 1984, detectaram a presença de IgG e IgA e juntamente com a participaçào do C' tentaram explicar as lesôes glomerulares.

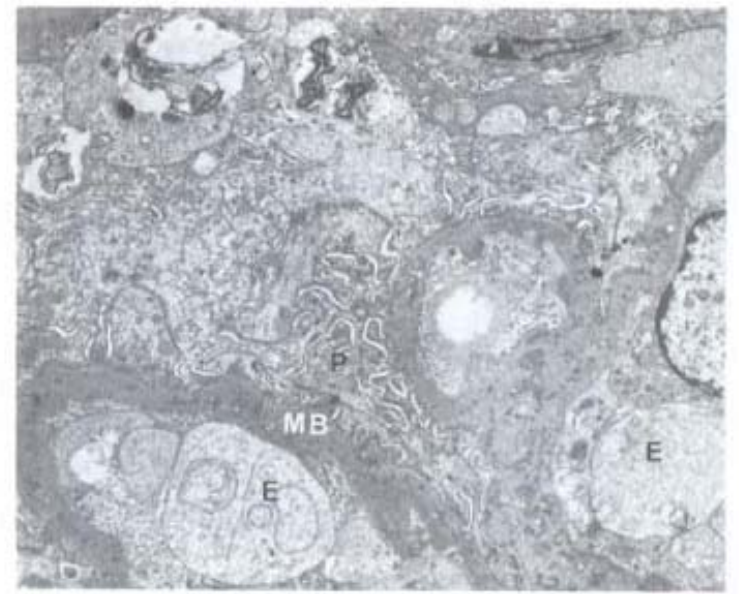

Fig. 5 - Cào infectado naturalmente com a L. (Leishmania) chagasi, Rim esquerdo. Parte de um glomèrulo mostrando fenómenos regressivos do podócito ( $P$ ) com fusào de seus pés junto da MB, que se encontra espessada e chela de depositos eletrondensos. Tumefaçao do endotelio (E). x 7880 .

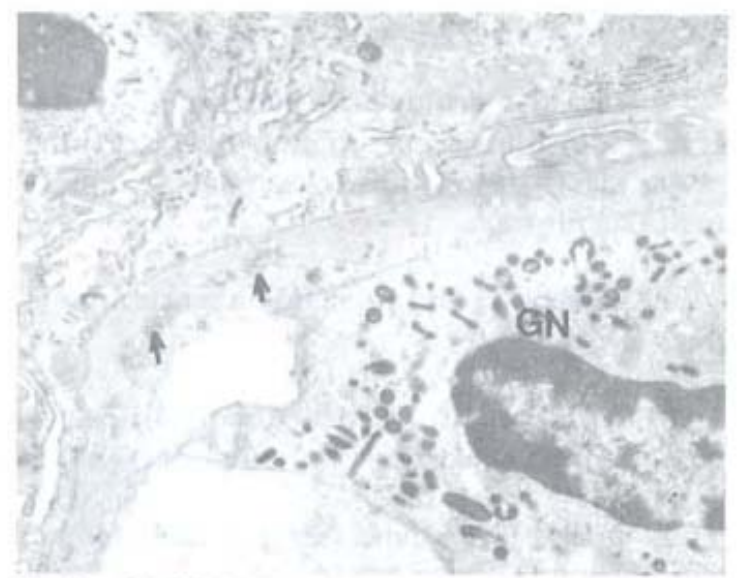

Fig. 6 - Câo infectado naturalmente com a $L$. (Leishmania) chagasi. Rim direito. Alça glomerular com um granulócito neutrónilo (GN) na luz e emitindo pseudópodos, aparentemen te, fazendo corpo com a MB espessada e com depósitos eletron densos (setasi. x 20140.

Também é possível que no cāo, como foi visto no hamster (BUNN MORENO et al., 1985), haja uma ativação policlonal $B$ bem como uma supressão das células $\mathrm{T}$ devido a presença dos antigenos parasitários, dada a intensa plasmo. citose observada nos órgãos linfáticos e nos rins. 
TAFURI, W. L.: MICHALICK. M. S. M.: DIAS, M.: GENARO, O: LEITE, V. H. R: BARBOSA. A. J A.: IBAMBIRRA. E. A.; COSTA, C. A. da; MELO, M. N. \& MAYRINK. W. - Fstudo, au microscopio optico e cletronico. do rim de caes natural e experimentalmente infectados com Ieishmania (Leishmania) chagasi. Kev. Inst. Med. trop. S. Paulo, 31(3): $139145,1989$.

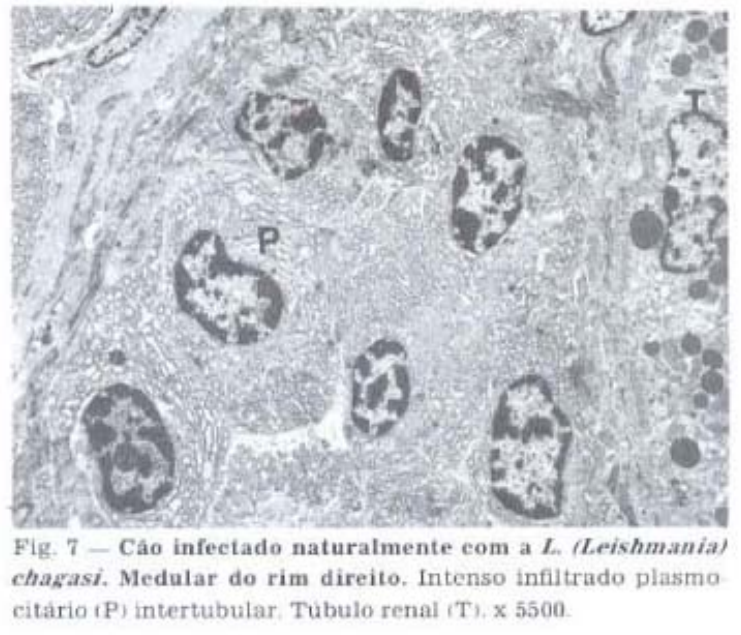

De acordo com os dados de necropsia e clini colaboratoriais, acreditamos poder excluir qual quer fator etiológico que pudesse interferir na interpretaçảo da glomerulopatia leishmanióti ca. Assim sendo, podemos concluir que nos oito rins estudados havia:

1. Uma glomerulonefrite mesangioprol fera tiva, focal ou difusa com pronunciada hipertrofia e hiperplasia das células mesangiais, e alarga mento da matriz:

2. Depósitos eletrondensos na matiz mesan gial;

3. Espessamento da MB com depósitos ele trondensos na sua espessura e sub endoteliais:

4. Nefrite intersticial intertubular crónica, com exsudação de plasmócitos e macrófagos: estes, às vezes corados pela técnica de imunope roxidase usando se soro anti-Leishmania.

\section{Degeneraçāo tubular.}

Baseados nestes resultados acreditamos que haja necessidade de estudos experimentais controlados do calazar canino, nāo só pela sua importância epidemiológica na transmissào da doença como pela semelhança das alteraçōes re nais encontradas em relaçäo ao que ocorre no calazar humano. Estudos sistemáticos dos mecanismos patogenéticos estão sendo desenvol vidos com o intuito de esclarecer pontos obscu ros da doença.

\section{SUMMARY}

Optical and electron microscopical studies of canine kidney naturally and experimentally infected with Leishmania (Leishmania) chagasi

Two naturally infected dogs (male and fema le) from Teófilo Otoni (MG-Brazil) were main tained for 18 months in our laboratory. Two other dogs, two months old males were infected with $1 \times 10^{6}$ promastigotes of $\mathrm{MHO} \mathrm{BR} / 70 \mathrm{BH} 46$ Leishmania (Leishmania) chagasi strain, endo. venous route, and autopsied after 10 months and two years

The main findings concerning the kidney were: 11) focal or diffuse mesangial glomerulo nephritis with proliferative and enlargement of mesangial cells: $(2)$ increase in thickness of base ment membrane with electron-dense deposits; (3) chronic interstitial nephritis with intense exudation of plasmocytes; (4) cloud swelling of renal tubules.

The authors discuss the probable pathoge netic mechanisms

\section{AGRADECIMENTOS}

Aos bioteristas Antônio Leides de Resende e Éder Rodrigues Coelho e aos técnicos Raimun do Luiz Pinto e Terezinha Lucy Mendonça Dutra pelos auxilios prestados.

\section{REFERENCIAS BIBLIOGRAFICAS}

1. AGU, W. E. FARRELL. J. P. \& SOULSBY. J L. - Prolife rative glomerulonephritis in experimental leishmania donovani infection of the golden hamster. Comp. immun. Microbiol. infect. Dis., 4: 353368.1981

2. ALENCAR. J. E. - Calazar canino. Contribuięa para o pstudo da epidemiologia do calazar no Brasil. Forta leza, 1959 (Tese)

3. ANDRADE, Z. A. \& YABUKI, K. - A nefropatia do cala zar Rev. Inst. Med. trop. S. Paulo, 14: 5154,1972

4. AYALA, M. A. R. -.. Alteracoes renais no calazar canino expontánco. Rev. Soc. bras. Med. trop., 7: 353 358, 1973. 
TAFURI, W. L.; MICHALICK. M. S. M.: DIAS, M.; GENARO, O.: LEITE, V. H. R.; BARBOSA, A. J. A.: BAMBIRRA, E. A.; COSTA, C. A. da: MELo, M. N. \& MAYRINK. W. - Estudo, ao microscópio óptico e eletrónico, do rim de càes natural e experimentalmente infectados com Leishmania (Leishmania) chagasi. Rev. Inst. Med. trop. S. Paulo, 31(3): 139 145, 1989

5. BARBOSA A. J A.; COSTA. C. A. da; RAMIREZ. L. E.; TAFURI. W. L.: RASO. P. \& MAYRINK, W. - Antibodies against Leishmania species react more strongly with Trypanosoma cruzi amastigotes than with the homologous amastigotes. An immunocytochemical study. Mem. Inst. Oswaldo Cruz, 81 isuppl I: 131, 1986

6. BOGLIOLO, L. -- Nova contribuiçao au conhecimento da anatomia patológica da leishmaniose visceral. A propo sito de um caso brasileiro e com especial referencia a fibro se hepatica leishmaniótica. Hospital (Rio de J.), 50: $393440,1956$.

7. BUNN MORENO, N. M.; MADEIRA, E. D.: MILLER, R.; MENEZES, J. \& CAMPOS NETO, A. - Hypergamaglobulinemia in Leishmania donovani infected hamster: possi ble association with a polyclonal activator of $\mathrm{B}$ cells and with suppressive of $\mathrm{T}$ cell function. Clin. exp. Immunol., 59: 427434,1985 .

8. BRENER, Z. - Calazar canino em Minas Gerais. Belo Horizonte, 1957. (Tese).

9. CHUNG, H. L.: HOEPPLI. R. \& FENG, L. C. - Histopa thological observations in twelve cases of canine leishma niasis in Peiping. Chin. med. J., 3: 212 223, 1940.

10. CORBEIL, L. B; WRICHT GEORGE, J : SHIVELY, J N.: DUNCAN, G. B.: LaMOTTE, G. B. \& SCHULTZ, R D. - Canine visceral leishmaniasis with amyloidosis: an immunopathological case study. Clin. immunol. Immunopath., 6: 165173, 1976 .

11. DEANE, L. M - Leishmaniose visceral no Brasil. Estudo sobre reservatorios e transmissores realizados no Estado do Ceará. Rio de Janeiro. Serviço Nacional de Educaçáo Sanitária, 1956. (Tese)

12. DE BRITO, T.; HOSHINO SHIMIZU, S: AMATO NETO V.; DUARTE, M. I. S. \& PENNA, D. O. -- Glomerular involvement in human kala azar: a light, immunofluores cent, and electron microscopic study based on kidney biopsies. Amer. J. trop. Med. Hyg., 24: 9 18, 1975.

13. DE PAOLA, D. \& SILVA, J. R. - Histopatologie der kala Azar. Ergebn. allg. Path. path. Anat., 39: 1-52, 1966.

14. DUARTE, M. I. S. - Aspectos renais do calazar experimental. Contribuição da analise morfométrica da célula mesangial ao conhecimento da patogenese da amiloidose. Sảo Paulo, 1975. (Tese de doutoramento-Escola Pau lista de Medicina)

15. DUARTE, M. I. S.: SESSO, A. \& BRITO, T. - Relation ship between glomerular mesangial cell proliferation and amyloid deposition as seen by ultrastructural and mor phometric analysis in experimental kala azar of the hams ter. Amer. J. Path., 92: 85 98. 1978.
16. DUARTE, M. I. S.; SILVA, M. R. R.; GUTO, H.: NICODE MO. E. L. \& AMATO NETO, V. - Interstitial nephritis in human kala azar. Trans. roy. Soc. trop. Med. Hyg., 77 $531537,1983$.

17. LUARTE, M. I. S. \& CORBETT, C. E. P ... Histopatho logical and uitrastructural aspects of interstitial pneumo nitis of experimental visceral leishmaniasis. Trans. roy. Soc. trop. Med. Hyg., 78: 683688,1984

18. GEORGE, J. M., NIELSEN, S. H.; SHIVELY, J. N.; HO PES, S. \& MROZ, S. - Canine leishmaniasis with amyloi dosis. Vet. Path., 13: 365-373, 1976.

19. HINGHAIS, N ; ZWIBAUM, A. \& RICHET, G - Les lé sions précoses de l'amylose experimentale du hamster Nephron, 6: 16, 1964

20. MCCONNEL, E. E.; CHAFEE, E. F.; CASHELL, I. G. \& GARNER, F. M. - Visceral leishmaniasis with ocular in volvement in a dog. J. Amer. Vet. med. Ass., 156: 197203 1970.

21. NICODEMO, E. L.; DUARTE, M. I. S.; NICODEMO, A C. \& AMATO NETO, V. - Aspectos clinico laboratoriais da nefrite intersticial da leishmaniose visceral. Rev. paul. Med. 102: 19 22, 1984 .

22. OLIVEIRA, V. A.; ROQUE BARREIRA, SANTORI, A.; CAMPOS NETO, A \& ROSSI, M. A. - Mesangial prolife rative glomerulonephritis associated with progressive amyloid deposition in hamsters experimentally infected with Leishmania donovani. Amer. J. Path., 120: 256262 , 1985.

23. TOME, G.S. - Contribuiçāo ao estudo da anatomia pato lógica da leishmaniose visceral canina espontánea, com especial referencia ao foco do Ceará. (Apresentado ao X III Congresso Brasileiro de Higiene, Fortaleza, CE, 1956).

24. UEBEL, H. -... Uber ciweiss stoffwchesel sterungen bei in fantiler visceraler leishmaniose unter besenderer berack sichtigung der pathologisch anatomischen. Veranderungen $Z$. tropenmed. Parasit, 2: 237, 1951.

25. WEISINGER, J. R: PINTO, A.; VELAZQUEZ, G. A. BRONSTEIN, I.; DESENE, J. J.; DUQUE, J. F.; MONTE NEGRO, I.; TAPANES, F. \& ROUSSE, A. R. - Clinical and histological kidney involvement in human kala azar Amer. J. trop. Med. Hyg., 27: 357 359, 1978

Obs: A nomenclatura do parasito utilizada foi atualizada se gundo LAINSON, R. \& SHAW, J. J. - Evolution classifi cation and geographical distribution. In: The Leishmaniasis vol. 1. London, Academic Press, 1987.

Recebido para publicaçáo em 25/5/1988. 